\title{
Just societies, health equity, and dignified lives: the PAHO Equity Commission
}

The USA is the richest country in the Americas and its residents enjoy good health: female life expectancy is 81 years and male is 76 years. Haiti is the poorest country in the Americas; its residents suffer poor health: female life expectancy is 66 years and male is 61 years. US gross national income (GNI) is about US\$59 000 per person. In Haiti, it is just over $\$ 1800$ per person, adjusting for purchasing power. ${ }^{1}$

The USA and Haiti conform to the pattern of rich countries with healthy people and poor countries with unhealthy people. Except it is not so simple. One exception comes from comparisons between countries. In Costa Rica and Cuba, life expectancies are a year longer than in the USA. But their GNI is a fraction of the US level: $\$ 16000$ per person in Costa Rica ${ }^{1}$ and of the same order in Cuba. Then there are countries such as Argentina and Chile with similar levels of national income, but Chile's life expectancy is 2 years longer for women and 4 years longer for men than Argentina's. The USA may be the richest country in the Americas, but there are at least eight countries with longer life expectancy. Canada, for example, with national income per person a quarter lower than the USA, has female life expectancy a full 3 years longer and male life expectancy 4 years longer than in the USA. ${ }^{1}$ There are many routes to good health for a country and high national income is only one of them.

Another exception comes from looking at health inequalities within countries that can rival the inequalities between countries. In the US city of Baltimore, men in the poorest communities have life expectancy close to that in Haiti, whereas men in the richest neighbourhoods have life expectancy that is better than that in Canada. Such inequalities within countries are widespread. In Chile, a man with low education can expect to live 11 years fewer than a man with university education.

It is to address inequalities such as these that the Commission of the Pan American Health Organization on Equity and Health Inequalities in the Americas was set up by the Director of the Pan American Health Organization (PAHO), Carissa Etienne. The PAHO Equity Commission's starting point is that health is a worthwhile goal for individuals and for communities. Certainly, there are good instrumental reasons for improving health: good health may be a route to individuals enjoying flourishing and productive lives; a healthier population may make economic sense for a country. But that is not our central concern. Health is more than a means to some other end. Human wellbeing is an end in itself. Better 
health and greater health equity will come when life chances and human potential are freed to create the conditions for all people to achieve their highest attainable standard of health and to lead dignified lives. On September 24, 2018, the Executive Summary of the report of the Commission is published and presented to a meeting of PAHO's governing bodies, its Directing Council, in Washington DC, USA. ${ }^{2}$

The evidence brought together by the PAHO Equity Commission shows that much ill health is socially determined. Health inequalities arise because of the conditions in which people are born, grow, live, work, and age. Similarly, health inequalities within countries are mostly the result of the social determinants of health. As the PAHO Equity Commission shows, initiatives on education and social inclusion, for example, will have health and other societal benefits.

The effect of social determinants of health is seen at the beginning of life. ${ }^{3}$ In most countries in the Americas, the chance of a child dying before the age of 5 years is linked with parents' income-the lower the income, the higher the mortality. ${ }^{4}$ In Guatemala, for example, in 2014, the under- 5 mortality rate was 56 per 1000 livebirths in the poorest fifth of families and 20 per 1000 livebirths in the richest fifth. ${ }^{5,6}$ In nearby Colombia, by contrast, the under-5 mortality in the richest fifth was 7 per 1000 livebirths in $2015^{5,6}$ - a rate that shows what should be achievable. Across the Americas, children's lifelong development and outcomes in education, income, health, and wellbeing are closely aligned with their parents' situation.

Good health requires not only access to health care, but also action on the social determinants of health. Indeed, so close is the relation between features of society and health that, as the PAHO Equity Commission argues, health and health equity are important markers of societal progress.

In addition to the challenge of addressing social and economic inequalities, the PAHO Equity Commission's work has identified climate change, environmental threats, relationship with land, and the continuing impact of colonialism, racism, and the history of slavery as important factors that slow progress toward the goal for people in the region to lead a dignified life and enjoy the highest attainable standard of health.

It is an important moment to publish this report. Inequality dominates the Americas. Too much inequality damages social cohesion, leads to unfair distribution of life chances, and to health inequalities. Yet at the same time, the region has been at the forefront of acknowledging the human right to the highest attainable standard of health with most countries signing international protocols on economic, social, and cultural rights. ${ }^{7-12}$ 
Implementation of the recommendations of these agreements is the challenge for political, professional, civil society, and community leaders.

The PAHO Equity Commission's conceptual framework summarises our approach to analysing the evidence and to formulating recommendations (figure). The framework is based on the Commission on the Social Determinants of Health ${ }^{13}$ but goes beyond it, with more emphasis on: colonialism, structural racism, and the importance of relationships to land; the environment and climate change; human rights; and inequities according to gender, ethnicity, sexual orientation, life stage, and disability. A particular focus is on health disadvantage of Indigenous people and those of African descent. The PAHO Equity Commission recognises the inter-relations between these social determinants of health. Being poor, Indigenous, female, and displaced from land, for example, may bring greater health disadvantage than any one of these alone. We place emphasis on leading a dignified life as a desired outcome aligned with greater health equity. Monitoring and evaluation of health equity and the social determinants of health must be important components of action.

The PAHO Equity Commission's recommendations for action follow this conceptual framework. Although we endorse a reorientation of health services toward prevention, we recognise that exhorting people who live under difficult conditions simply to adopt healthy behaviour may be useless, or worse. Reducing health inequities will remain elusive unless the structural drivers are addressed. A First Nations child in Canada is not at increased risk of suicide because her parents did not heed advice on child-rearing but because the consequences of colonialism and social inequalities endure. Not only are disadvantages associated with low socioeconomic position in play, but when Indigenous peoples in Canada are deprived of their traditional relation to land, it, too, is a social determinant of health $-a$ structural driver of inequalities. Similarly, in Colombia, the high mortality from violence among young men of African descent can partly be traced back to the persisting effects of colonialism and racism.

Structural drivers-eg, large and growing economic inequalities, privileging of the private sector over recognition of the importance of a flourishing public domain, ignoring the environment-must all be tackled in the pursuit of health equity. Our recommendations do not proceed on the assumption that addressing these structural drivers is easy. But health inequities provide powerful reasons for doing so. 
Governments can provide funding to address inequalities in early child development, in education and training, in unemployment benefits. Welfare can support incomes as can adequate pension arrangements. Civil society, too, is vital in delivering programmes and in changing the climate of opinion. Gender-based violence blights the lives of too many women throughout the Americas. Action on many of the social determinants of health will help militate against such violence; but it will also take attitudinal changes. In fact, ensuring the rights of women to lead full, dignified lives free of discrimination-with education, security, and better health for them and their communities-is an exemplar of a clear way forward. Human rights mechanisms are important instruments of achieving change. At the heart of the Commission's purpose is ensuring the right of all people in the Americas to lead lives of dignity and enjoy the highest attainable standard of health. We call on all governments to act.

\section{Michael Marmot}

Institute of Health Equity, UCL Department of Epidemiology and Public Health, University College London, London WC1E 7HB, UK

m.marmot@ucl.ac.uk

I am Chair of the PAHO Commission on Equity and Health Inequalities in the Americas. I declare no other competing interests. The other members of the PAHO Commission on Equity and Health Inequalities in the Americas are: Victor Abramovich; Mabel Bianco; Cindy Blackstock; Jo Ivey Bufford; Paolo Buss; Nila Heredia; Pastor Murillo; Tracy Robinson; María Paola Romo; David Satcher; Cesar Victora. Also involved with the Commission are: the UCL IHE secretariat: Jessica Allen, Peter Goldblatt, Joana Morrison; and the PAHO Cross Cutting Theme Group

1 World Bank. International Comparison Program Database. 2017. https://data.worldbank.org/indicator/SP.DYN.LEOO.MA.IN (accessed Sept 20, 2018).

2 Commission of the Pan American Health Organization on Equity and Health Inequalities in the Americas. Just societies: health equity and dignified lives. Executive Summary of the Report of the Commission. Washington, DC: Pan American Health Organization, 2018

3 Marmot M. Social determinants of health inequalities. Lancet 2005; 365: 1099-104.

4 Commission on Social Determinants of Health. Closing the gap in a generation: health equity through action on the social determinants of health. Final report of the Commission on Social Determinants of Health. Geneva: World Health Organization, 2008. 
5 WHO. Global Health Observatory data. Inequality in child mortality. 2018.

http://www.who.int/gho/health_equity/outcomes/under5_mortality/en/ (accessed Sept 20, 2013).

6 ECLAC. Social Panorama of Latin America, 2016. Santiago: Economic Commission for Latin America and the Caribbean, 2017.

7 PAHO. Resolution CE156.R6: strategy and plan of action on strengthening the health system to address violence against women. Washington DC: Pan American Health Organization, 2015.

8 PAHO. Resolution CE156.R3: Plan of action on workers' health. Washington DC: Pan American Health Organization, 2015.

9 PAHO. Resolution CD55.R13 Health of migrants. Washington DC: Pan American Health Organization, 2016.

10 PAHO. Resolution CD53.R7: Plan of action on mental health. Washington DC: Pan American Health Organization, 2014

11 PAHO. Resolution CD53.R12: Plan of action on disabilities and rehabilitation. Washington DC: Pan American Health Organization, 2014.

12 PAHO. Resolution CSP29.R3 Policy on ethnicity and health. Washington DC: Pan American Health Organization, 2017.

13 Solar O, Irwin A. Towards a conceptual framework for analysis and action on the social determinants of health. Geneva: Commission on the Social Determinants of Health, World Health Organization: 2005. 